\title{
contexto
}

Fotografía y feminismo durante la transición española

vol 16 / Jun.2017 55-74 pp Recibido: 11-12-2016 - revisado 07-02-2017 - aceptado: 03-03-2017 


\section{COLITA IN CONTEXT}

PHOTOGRAPHY AND FEMINISM DURING THE SPANISH

TRANSITION

\section{ABSTRACT}

The work that the Catalan photographer Colita (Barcelona, 1940) did during the seventies was allied to the feminist movement, resurgent in Spain after Franco's death. Her photographic practices, those that made visible the most important needs of Spanish feminism during that time, will be studied in this article: her work for the journal Vindicación feminista (1976 and 1979) and the photobook Antifémina (Editora Nacional, 1977), made in collaboration with María Aurèlia Capmany. Colita's erotic photography of these years will also be examined -a much more problematic production in connection with the feminist proposals of this time. On the one hand, feminists politicized sexual pleasure but, on the other, they railed against "destape" images, because this trend objectified the nude female body. Nevertheless, Colita's erotic work allows a queer reading or at least presents an alternative framework to heterosexual desire and the gaze.

\section{Keywords}

Photography, Feminism, Eroticism, "Destape”, Spanish transition.

\section{RESUMEN}

El trabajo que desarrolló la fotógrafa catalana Colita (Barcelona, 1940) durante la década de los setenta fue aliado del movimiento feminista que se recompuso en el Estado español tras la muerte de Franco. En este artículo estudiaremos sus prácticas fotográficas al respecto, aquellas que visibilizaron las demandas más importantes del feminismo español del momento: su trabajo para la revista Vindicación feminista (1976- 1979 y el fotolibro Antifémina (Editora Nacional, 1977), que hizo en colaboración con María Aurèlia Capmany. En segundo lugar atenderemos a la fotografía erótica que también desarrolló Colita durante estos años, una producción más problemática a la luz de las propuestas feministas del momento. Por un lado estas politizaron el placer sexual pero por otro se manifestaron en contra de las imágenes del "destape", por cosificar el cuerpo desnudo de las mujeres. Sin embargo, este trabajo permite una lectura queer o al menos presenta una estructura disidente con el deseo o la mirada heterosexual.

\section{Palabras Clave}

Fotografía, feminismo, erotismo, "destape", transición española. 


\section{INTRODUCCIÓN}

El estudio de la praxis fotográfica de Colita ${ }^{1}$, sobrenombre de Isabel Steva Hernández (Barcelona, $1940)^{2}$, nos permite la reflexión sobre la intersección entre fotografía y feminismo en la España de los años setenta, un tema poco explorado hasta la actualidad. El trabajo fotográfico de Colita presenta algunas de las problemáticas clave que el movimiento feminista de la España de los setenta tuvo que afrontar en torno a los medios de comunicación: por un lado hizo un necesario trabajo de visibilización de sus demandas fundamentales, en la línea del feminismo de la segunda ola. Por otro, se inmiscuyó en el territorio de la fotografía erótica, un aspecto realmente difícil de incorporar por los feminismos hegemónicos, especialmente en ese momento, en el que se sucedía el auge del cine del "destape" en España ${ }^{3}$. Cierta heterogeneidad de las prácticas fotográficas de Colita en torno al cuerpo, la sexualidad y el erotismo nos llevan a proponer una lectura queer de esta parte de su trabajo; una interpretación de lo queer según la propuesta de Ahmed (2006), en la que este concepto se entiende como una (des)orientación tanto sexual como política. Una lectura que reconocemos posicionada en el presente de la escritura del artículo y anacrónica, aunque quien escribe estas líneas piensa que el ejercicio de escritura histórica siempre tiene un componente de anacronismo.

Analizaré el trabajo fotográfico de Colita en las páginas de la revista Vindicación feminista, una revista creada en Barcelona en julio de 1976 por Carmen Alcalde y Lidia Falcón, y que tuvo una corta pero intensa andadura durante los años de la transición, publicándose su último número en 19794 . También nos detendremos en el proyecto más emblemático relativo a la militancia de Colita en el feminismo, me refiero al fotolibro Antifémina. Publicado en 1977 por la vieja editorial franquista Editora Nacional. Fue elaborado al alimón con la escritora Maria Aurèlia Capmany, un referente en la reemergencia del feminismo en la Cataluña a partir de los años sesenta (Bassas, 2013, p. 215), quien fue la encargada de escribir los textos mientras que Colita seleccionó las fotografías de su propio archivo (Calvo, 2014, p. 236).

El debate relativo al "destape" y al erotismo a través de las prácticas fotográficas lo podremos analizar con mayor profundidad en la ambigua obra que hemos encontrado publicada en los anuarios de fotografía Everfoto. Sorpresivamente ésta no apareció en Interviú ${ }^{5}$ sino en otras publicaciones consideradas más sofisticadas como Repórter ${ }^{6}$, o especialmente Bocaccio (19701974), una publicación explícitamente dirigida a un público masculino con alto nivel adquisitivo y de clase privilegiada.

\section{MUJERES, FÉMINAS, FEMINISTAS}

La revista Vindicación feminista surgió del impulso provocado por el éxito rotundo de las I Jornades Catalanes de la Dona, celebradas en Barcelona en mayo de 1976. Este encuentro fue clave en la reconstrucción del movimiento feminista tras la muerte de Franco. Emergió en éste lo que Llinás Carmona (2008) ha llamado el "sujeto imprevisto", por el gran e inesperado número de mujeres que participaron ${ }^{7}$ y el sorpresivo impacto que las jornadas tuvieron en la opinión pública. Las mujeres, siguiendo las ideas Llinás Carmona, se constituyeron como un nuevo sujeto histórico emergente, y demostraron no solo su poder de convocatoria sino sus posibilidades para acometer cambios en las estructuras sociales: distintos grupos feministas fueron capaces de expresar una serie de demandas consensuadas de manera colectiva, dirigidas tanto al gobierno como a la sociedad en su conjunto. Éstas fueron: la amnistía para adúlteras y 
prostitutas; la legalización del divorcio, de la anticoncepción y del aborto; la lucha por sexualidad libre y la coeducación, así como el derecho al trabajo sin discriminaciones y el reconocimiento de los derechos sociales para las trabajadoras del hogar (Uría Ríos, 2009, p. 67 y ss.).

En el nivel de planteamientos discursivos y contenidos textuales Vindicación feminista es aún a día de hoy un referente en la historia del feminismo en el Estado español, pues retomó debates desatendidos desde la década de los treinta, como el trabajo del ama de casa y la prostitución, pasando por la maternidad, el divorcio y la sexualidad, también la practicada entre mujeres -a pesar de que se sacrificó la "realidad encarnada y concreta" de las lesbianas para convertirse en un "recurso teórico" como argumenta Begoña Pernás (2012, p. 406). Colita tuvo un papel destacado desde el principio en la revista: empezó haciendo fotografías para ilustrar artículos, rápidamente pasó a encargarse de las portadas, y finalmente dirigió el conjunto del diseño visual de la publicación, haciendo fotografías ad hoc y llevando a cabo el trabajo de archivo en busca de imágenes diversas.

La propuesta de Colita en las páginas de Vindicación fue la de visibilizar — un claro objetivo del feminismo de la segunda ola-, no sólo la vida y la cultura de las mujeres sino también las principales demandas de su lucha política. Este compromiso, que sin duda estaba muy posicionado durante aquellos años, tiene un enorme valor como testimonio y memoria, pues ilustra muchas de las acciones y preocupaciones del feminismo español de los años setenta, que de otra manera apenas habrían tenido registro. Al hacer imagen de las manifestaciones de las feministas (Fig. 1) o del movimiento gay, al retratar mujeres fuera de la norma heteropatriarcal construyó posibilidades de existencia; desde luego amplió el canon de lo visible y de lo representable. Se convirtió en testigo de la militancia feminista, algo esencial a la hora de determinar presencia y memoria.
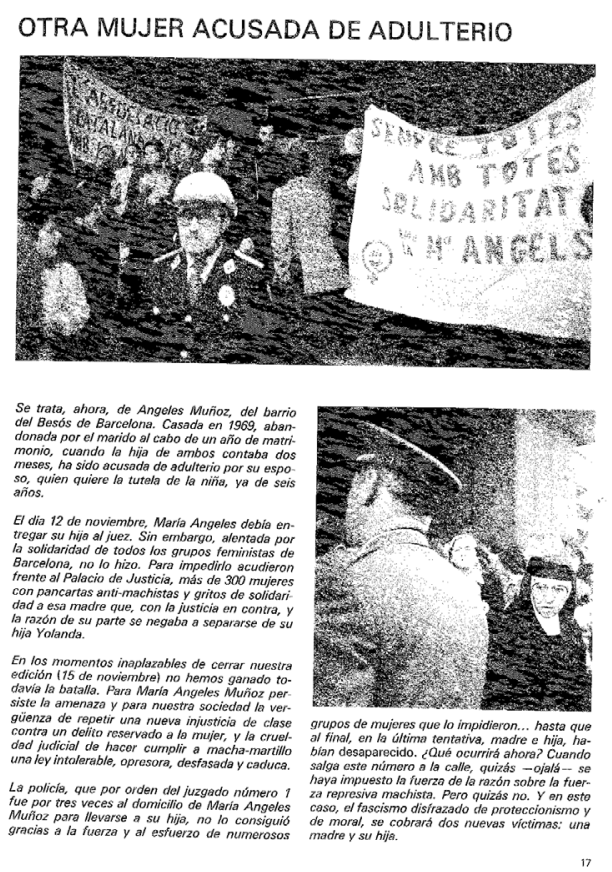

Figura 1. Vindicación Feminista, no 6, diciembre de 1976, p. 17. Fotos: Colita. 


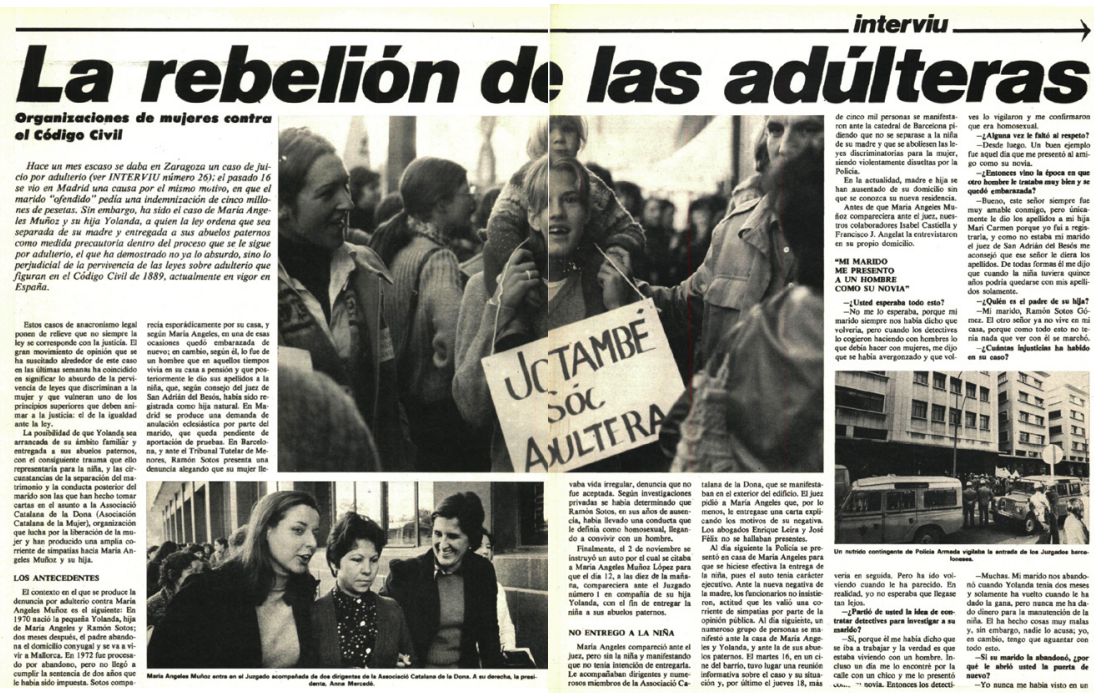

Figura 2. Interviú, no 28, 25 de noviembre de 1976, pp. 78 y 79. Fotos: Colita

¿Qué significa para Colita el hacer una fotografía feminista en la España de los setenta? Como mujer "progresista", "humanista" y "de izquierdas" (tal y como ella misma se define), no concibió otro posicionamiento que el feminista ${ }^{8}$. Colita describe su condición de fotógrafa durante estos años como la de una trabajadora de la prensa, eso sí, siempre en publicaciones "de izquierda" como Destino, Triunfo o Gaceta llustrada. Sus objetivos, más que llevar a cabo una reflexión teórica sobre el medio para transformar sus estructuras, eran los de hacer una fotografía profesional que sirviera para ilustrar los artículos del diario o la revista para la que trabajaba como freelance. Colita se describe a sí misma como perteneciente a una generación de fotógrafas feministas más "eficientes" que interesadas en "hablar del sexo de los ángeles". Su posicionamiento fue el hacer una fotografía que califica de testimonial y eficaz, y que entiende como veraz. Frente a otras apuestas relativas a la fotografía documental, que también se estaban llevando a cabo en la Barcelona de la transición, como la desarrollada en Centre Internacional de Fotografia Barcelona, donde se apostó por el reportaje social extendido en el tiempo frente a la inmediatez de la fotografía de prensa, el trabajo de Colita se enmarcó bien dentro del foto reporterismo clásico. Por otro lado, tampoco se implicó en las actividades feministas ajenas a los medios de comunicación más o menos hegemónicos, a excepción de su activa participación en Vindicación feminista, como el bar-biblioteca y editorial LaSal (abierto en 1977). Esta fue una de las primeras iniciativas barcelonesas de autogestión feminista y donde se expuso únicamente arte hecho por mujeres y se publicaron importantes títulos de pensamiento feminista (Almerini, 2014).

Su concepción fue y sigue siendo la de hacer una fotografía pragmática; de este modo también entendió su labor como reportera pues recuerda su método de trabajo de la siguiente manera: "me daban un texto y pensaba cómo ilustrarlo, nada más". Entendió, como lo hicieron gran parte de sus colegas, la fotografía como un "arte utilitario", algo que quedó remarcado en la conversación publicada que mantuvo con Miserachs en 1988, donde el fotógrafo dice: "la fotografía sirve para comunicar un hecho. Si de lo que se trata es de elucubrar, mejor no coger una cámara. Hay más posibilidades con un lápiz, por ejemplo" (Colita, Xavier Miserachs, 1988, p. 56). Esta concepción de la fotografía responde a la actitud que mostró la generación de 
fotógrafos a la que perteneció Colita, conocida como la generación de los "profesionales" y contra la que reaccionó significativamente la generación más joven, conocida como la de los "creativos" (Ribalta, 2008).

Los referentes fotográficos de Colita fueron todos hombres; en el plano internacional Henri Cartier-Bresson y Richard Avedon; Francesc Català Roca, Oriol Maspons y Xavier Miserachs fueron sus principales influencias en Barcelona. Es interesante constatar como el paternalismo inherente a la "fotografía humanista" no es interpretado como un cuestionamiento o impedimento para Colita9. Al contrario, aseguraba que "el hecho de ser mujer nunca ha supuesto un problema", en un ambiente que califica de camaradería: "Todo lo aprendí de ellos y con ellos", dice refiriéndose a los fotógrafos (varones) de su generación. Y sobre todo, subraya que sus colegas fotógrafos la enseñaron a mirar: "Con ellos aprendí a mirar". No se planteó en ningún momento subvertir la mirada de sus maestros, su anhelo no fue hacer otra cosa sino lo mismo que ellos y, a ser posible, lo mejor posible.

La mirada es uno de los grandes temas de la crítica feminista en la cultura visual y artística, entendida ésta no como un fenómeno neutral, sino por el contrario como un elemento cultural activo de relaciones de poder. Sin embargo, en el planteamiento de teórico de Colita no encontramos el desarrollo de ningún tipo de problemática al respecto; es decir, no es que ella no practique o ejerza una mirada determinada, lo cual es imposible, sino que no despliega a través del discurso sobre su propio trabajo conceptualización al respecto. Esta postura no extraña si estudiamos el contexto de producción de discurso en la época en España. Pilar Aymerich, otra fotógrafa catalana que participó de la militancia feminista ha subrayado en una reciente conversación ${ }^{10}$ que las reflexiones en torno a la fotografía en la España de los setenta eran bastante pobres en el nivel de la crítica y la teoría en general, y por supuesto, en el plano del análisis y posicionamiento feminista y de género en particular. Por otro lado, si bien las fotógrafas y los fotógrafos no se preocuparon por estas cuestiones, tampoco hubo debates en el seno de las organizaciones feministas en relación a la cultura visual. Por ejemplo, es elocuente subrayar que no hubo reflexión en torno a la praxis fotografía, ni artística ni documental, ni en relación a la cultura visual, en los treinta números de Vindicación feminista. Tampoco se ofrecieron ponencias sobre estos temas en las distintas jornadas o encuentros feministas, ni hubo debates ni grupos de trabajo dedicados al tema de las imágenes y su construcción. Así lo constata la investigación de Maite Garbayo (2016, p. 47), quien subraya que existió una separación entre el ámbito artístico y las prácticas y teorías feministas, a pesar de auge del movimiento tras la muerte del dictador. Si existió un tema que fuera problematizado por las feministas y que se acercara de algún modo a las políticas y las críticas de las imágenes y la representación fue la crítica al "destape" y la pornografía, es decir, a ese amplísimo repertorio de cuerpos de mujeres desnudos o semidesnudos que inundaron revistas y pantallas de cine durante la transición, algo que veremos en la segunda parte de este ensayo.

De momento sigamos con la fotografía publicada de Colita durante los años de Vindicación feminista y observemos cómo hubo una importante migración de las fotografías entre distintos medios. En Vindicación feminista y en Interviú publicó, en ocasiones, sobre los mismos temas y utilizó las mismas fotografías. Por ejemplo, dando cobertura al caso de una mujer, Mari Ángeles, que fue acusada de adulterio en 1976 y que generó una importante movilización feminista ${ }^{11}$ (Figs. 1 y 2) o en los impactantes reportajes que hizo sobre hogares de asistencia social y manicomios ${ }^{12}$. A pesar de ello, el sentido de éstos es distinto. En los que se publicaron en el número 19 de Vindicación feminista ${ }^{13}$, que fueron los primeros en salir, el texto que acompaña 
las fotografías analiza la doble discriminación que significa ser mujer y enferma mental y cómo el esquema represivo que se presenta para la mayoría de la población femenina, basado en la familia y la domesticidad, genera ciertas rupturas y rebeldías que son entendidas socialmente como neurosis. Las mismas fotografías fueron publicadas también en Interviú y en el fotolibro Antifémina, pues sirvieron según Colita para ilustrar los mismos temas, por ejemplo: el trabajo femenino ${ }^{14}$; la prostitución ${ }^{15}$ (Fig. 3) o el divorcio ${ }^{16}$ (Fig. 4), como ya señalamos, algunas de las grandes preocupaciones feministas en la España de los setenta.

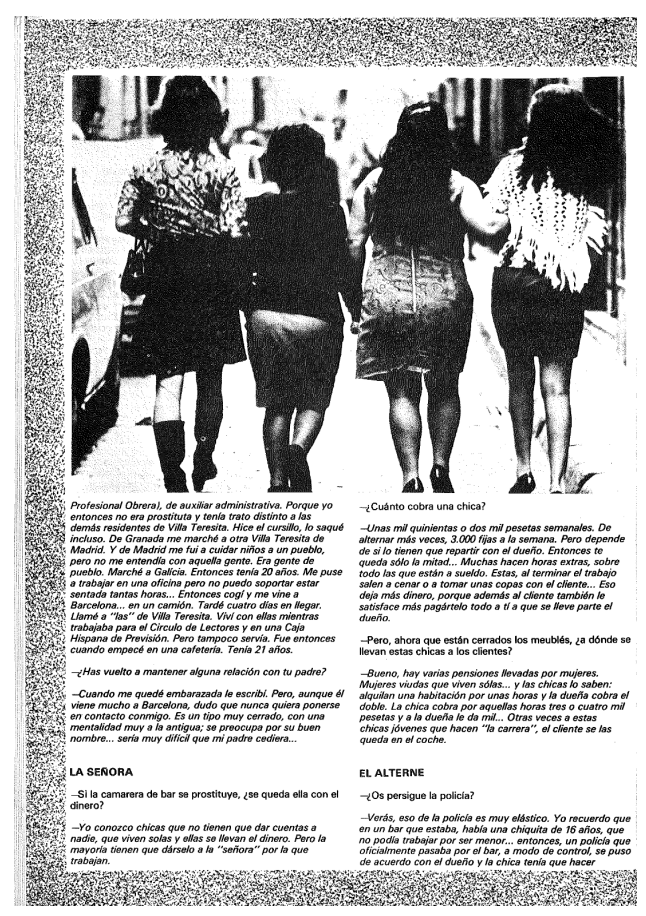

Figura 3. Vindicación feminista $\mathrm{n}$ ㄴ 2, agosto de 1976, p. 28. Fotos Colita

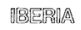 \\ A ladrillazo limpio \\ CONQUISTAR EL DIVORCIO
}
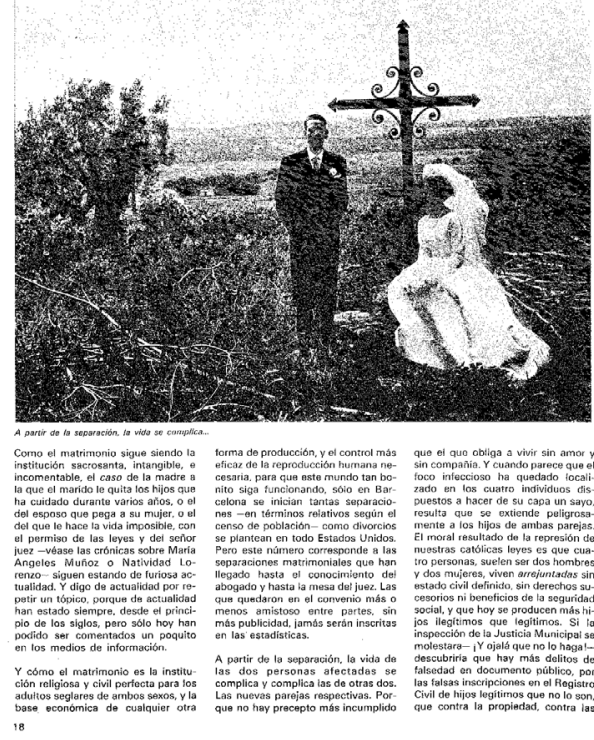

Figura 4. Vindicación Feminista nำ15, septiembre de 1977 , p. 18. Fotos Colita

Cuando le pregunté a Colita acerca de que si los distintos medios interfieren en el significado de las fotografías ella me contestó que no, sin embargo, si nos detenemos en estos ejemplos comparados creo que es evidente que hay una enorme diferencia en la recepción que generan las fotografías publicadas en la revista y en el libro, algo que no solo viene motivado por la mayor calidad de la fotomecánica y el papel del segundo. El libro fue elaborado de forma colaborativa entre Colita y Capmany y a diferencia de Vindicación feminista, donde la fotografía se buscaba para ilustrar un texto predeterminado, en este caso el discurso textual y visual se crearon en paralelo: "María Aurèlia y yo trabajábamos al alimón [...] con las fotos por un lado y ella iba escribiendo el texto, y lo pegaba arriba y abajo" (citado en Calvo, 2014, p. 236). Esta concepción de unicidad se hace evidente en el resultado final, donde se destaca el diseño elegante y sencillo que fue configurado, aunque cueste creerlo, de una manera bastante doméstica, pues ambas mujeres hicieron la maqueta sobre la mesa de la casa de alguna de ellas, con tijeras y pegamento. 
Sin embargo, consiguieron un resultado significativo, pues el voluminoso objeto sumerge al lector en una secuencia visual envolvente, y son las fotografías las que sobresalen en importancia y por encima del texto, a través de un ritmo marcado y muy dinámico donde se van contraponiendo composiciones texto/foto muy diferentes: desde dobles páginas con las fotografías ocupando toda la superficie e impresas a sangre, páginas con fotografías a sangre junto a una página con texto, o buscando diferentes juegos entre ambas, una serie de recursos verdaderamente eficaces a la hora de construir una narración visual. En todas estas composiciones, las imágenes ocupan como mínimo la mitad de la superficie del espacio de la doble página, pero su protagonismo es tal que en bastantes ocasiones hay dobles páginas sin texto (Fig. 5), u otras muchas en las que este solo ocupa un pequeño faldón en la parte inferior o en el lateral. El referido dinamismo también es favorecido por el uso de distintos planos (planos largos junto a primeros planos), que va creando acercamiento y temporalidad, lo que ayuda a emparentar el modo de hacer de este fotolibro con una secuencia cinematográfica.

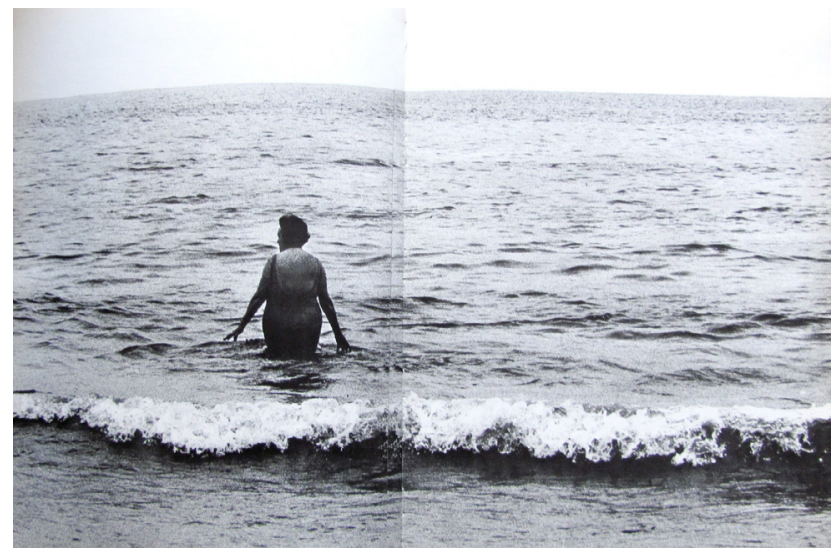

Figura 5. Antifémina. Madrid: Editora Nacional, 1977, pp. 8 y 9. MNCARS

Las tensiones entre texto e imagen, palabra y fotografía, documento y construcción subjetiva se hicieron evidentes en las primeras páginas del libro, donde Capmany (1977, p. 77) escribió:

Las imágenes que vamos ofrecer no son ni más ni menos que el reflejo en el ojo de la cámara, de lo que está ahí (...) No se trata de una realidad previamente ordenada, pero tampoco de lo que suelen ver los ojos distraídos del viandante (...) Los ojos de la cámara existen en función de los ojos del fotógrafo, qué duda cabe, pero yo me atrevería a decir que el fotógrafo adivina y la cámara desvela.

Para la escritora, las imágenes solo comunican en la medida en que generan palabras, y antes de que comience la secuencia fotográfica dice así: "las imágenes generan palabras, y éstas son algunas" (Capmany, 1977, p. 77). Lo que evidencia que el proceso, ahora discursivo y subjetivo, a la hora de crear Antifémina fue el inverso que el modus operandi seguido en Vindicación. En el caso del fotolibro fue a partir de la selección que hizo Colita de su archivo fotográfico de donde surgió el texto de Antifémina, es decir, fue la fotografía la que detonó el texto. Una fotografía que gracias al discurso textual que elabora Capmany se entiende desde un punto de vista algo más crítico que lo que hemos visto hasta ahora, algo que además se refuerza con las varias citas a Bertolt Brecht y su "asombro crítico" hacia lo acostumbrado, referencias que sin duda procedían de la formación como dramaturga de Capmany. 
A través de la intersección entre las categorías de mujer y vejez, matrimonio, trabajo, religión, prostitución, cuerpo, marginación, publicidad, indumentaria y piropo, es decir exposición pública, se tratan temas esenciales para desvelar el argumento principal del libro y el que da sentido al conjunto de estos diez capítulos: "visibilizar el reverso de la imagen de la fémina al uso" (Capmany, 1977, p. 10), la "antifémina", ese noventa por ciento de mujeres que "ni tienen veintiún años, ni miden metro sesenta y cinco, ni son casaderas. Es decir, que no corresponden al estereotipo femenino que ha prefabricado el macho en último tercio del siglo XX" (citado en Calvo, 2014, p. 235) ${ }^{17}$. Se establece por tanto una clara diferenciación entre las mujeres, ese noventa por ciento de mujeres corrientes que se "mueven, respiran o gesticulan" (Capmany, 1977, p. 10), frente a la feminidad, un concepto que rechazaban ambas artistas, pues lo entienden como "un conjunto de cualidades históricas y clasistas de un cierto tipo de mujer: de clase media, simple, que se perfuma, que hace lo que le han enseñado y no es otra cosa que un escaparate del hombre" (citado en Calvo, 2014, p. 235). Esa feminidad, asociada para Colita y Capmany invariablemente a la pasividad, hace que ambas se pregunten "la mujer del campo, la mujer de las fábricas, las mujeres gitanas ¿̇on en realidad mujeres?” (Capmany, 1977, p. 10).

De esta forma Antifémina tiene como tema principal y como cuestionamiento estructural uno de los grandes debates del feminismo de los años setenta y también de la actualidad; este es: ¿cuál es el sujeto político del feminismo?, o lo que es lo mismo, ¿qué significa ser mujer? El libro se hace eco y recoge de forma sorprendente las discusiones de la época, pero también antecede muchos de los debates que se desarrollaron a partir de los años ochenta y que continúan siendo activos y productivos en la actualidad.

Por un lado, es evidente la influencia de una de las más importantes lecturas teóricas que sobre feminismo se manejaba en la España de los setenta, El segundo sexo de Simone de Beauvoir, escrito en 1949, y que tuvo especial impacto en el pensamiento de Capmany ${ }^{18}$. En este libro ya se cuestionaba la categoría mujer como algo construido socialmente. Por otro lado, era en este momento (los años setenta) cuando se estaba discutiendo cuál era el origen de la opresión de la mujer, y si ésta era universal o transhistórica. Para responder a estas preguntas Gayle Rubin (1975) deshizo del nudo de lo biológico e ideó el sistema sexo/género, que posteriormente Butler (2007) dinamitó. El sistema sexo/género es el marco conceptual que se recoge de manera meridiana en Antifémina, a través de su particular división mujer y fémina.

Cuando Capmany y Colita se preguntaban si "la mujer del campo, la mujer de las fábricas, las mujeres gitanas ¿son en realidad mujeres?" resuena inmediatamente la aseveración de Monique Wittig (2006): "las lesbianas no somos mujeres", aunque ésta se planteó unos pocos años más tarde, en 1980. Con ella Wittig, como es evidente, no se refería a una cuestión biológica sino cultural y social: las lesbianas podían ser disidentes del orden heteropatriarcal pues con sus decisiones vitales se negaban a ser amantes de los hombres, a ponerse guapas para ellos, a trabajar gratis en el ámbito doméstico $24 / 7$ o a cuidar de sus hijos, evidenciando como la "heterosexualidad obligatoria" no era tanto una opción sexual como un régimen político y económico. Adrienne Rich (1986), en 1980, introdujo el concepto del "contínuum lésbico" para aludir a la importancia de los vínculos entre mujeres, no necesariamente filtrados por el deseo lésbico, como una resistencia al patriarcado. En estos mismos años, también, será cuando los movimientos conocidos como los feminismos negros critiquen el sujeto del feminismo occidental por ser demasiado blanco y burgués, y a los integrantes del movimiento antirracista por ser demasiado sexista y poco inclusivo con las mujeres (Combahee River Collective, 1977/2012). 
Por tanto esa pregunta que resonaba en Antifémina sobre quién es el sujeto tanto del patriarcado como del feminismo y cuáles son las normas que aparecen como invisibles pero que son esenciales en la constitución del régimen heteropatriarcal se tornaba en 1977 de rabiosa actualidad y venía a discutir un tema central y que tuvo enorme repercusión en las décadas posteriores. ¿Cómo respondió la parte fotográfica de Antifémina a estos cuestionamientos? El modo de hacer más habitual fue el retrato de mujeres otras, antiféminas: mujeres viejas, trabajadoras, obreras, prostitutas, a través de estilo entendido como documental, donde en algunas fotos se busca y se logra el efecto de instantánea a través de abruptos cortes y marcadas sombras, contrastes lumínicos muy fuertes y mucho grano (Fig. 6).

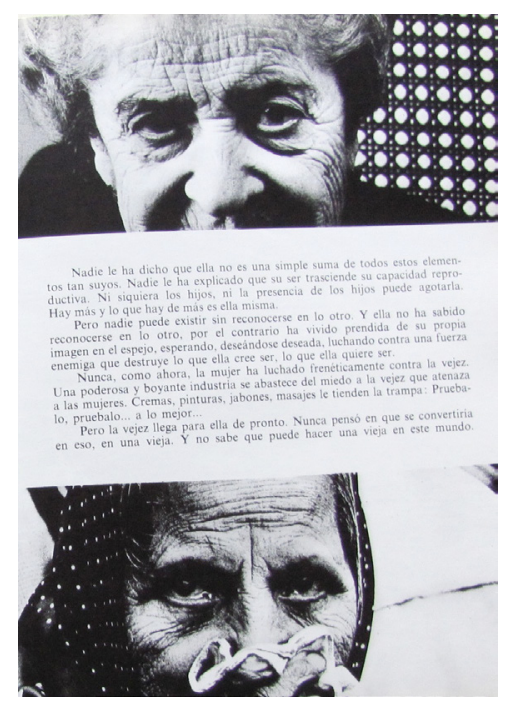

Figura 6. Antifémina. Madrid: Editora Nacional, 1977, p. 29. MNCARS

Pero por otro lado, la fotografía documental clásica que presenta Colita tiene innegables influencias estéticas y no es difícil encontrar en ella la tradición pictórica decimonónica del retrato idílico y complaciente del campesinado, por ejemplo la pintura de Millet (Fig. 7). En Antifémina también se recupera la tradición fotográfica de construcción del tipo, todo un tropo en la tradición y cultura fotográfica española. En sus fotografías, encontramos al respecto referentes dispares, desde Casiano del Alguacil a José Ortiz-Echagüe. Sin duda, también está presente esa reconocida influencia, esa manera de mirar que proviene del "documentalismo humanista". El ejemplo más evidente sería el voyeur Colom y sus fotos del barrio chino en presentes en Izas, rabizas y colipoterras (1964) (ver al respecto la Fig. 3), aunque también se pueden reconocer los trabajos sobre Barcelona de sus reconocidos maestros como Català Roca o Miserachs, especialmente el trabajo que hizo para el fotolibro Barcelona blanc i negre (1964) que a Colita le impactó. 


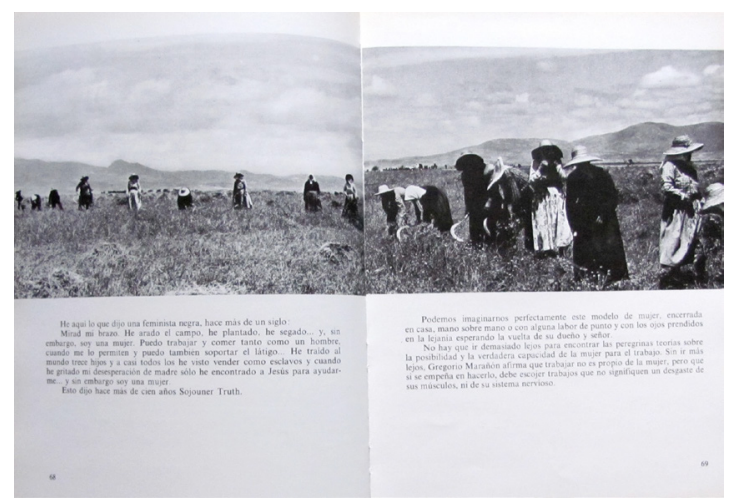

Figura 7. Antifémina. Madrid: Editora Nacional, 1977, pp. 68 y 69. MNCARS

\section{LA POLITIZACIÓN DEL PLACER}

Una de las partes más brillantes de Antifémina es el capítulo dedicado a la publicidad y a la exposición del cuerpo de las mujeres en el espacio público (Fig. 8), que lleva por título "Descuartizar un cuerpo". Bertolt Brecht aparece citado para argumentar que el objetivo de ambas artífices es "sorprenderse de lo acostumbrado" (...) "así que, hemos salido a la calle y nos hemos asombrado al ver tanto muslo suelto, tanto pecho agrandado, tanta pantorrilla pegada a las paredes y los faroles. No hemos visto mujeres, fíjense ustedes, sino trozos de mujeres" (Capmany, 1977, p. 113 y 115). El enfoque del capítulo tiene que ver con un diálogo crítico con la tendencia hispana que aquellos años hacía furor, conocida como "el destape": una brutal proliferación de cuerpos de mujeres desnudos en la cultura visual de los años setenta, que era entendida por gran parte de la población como una cosificación y clara objetualización de los cuerpos, una sexualidad hiper-presente y constante que surgía al tiempo que la censura era cada vez más inoperante o iba languideciendo hasta desaparecer definitivamente en 1978. Su preocupación por la cosificación del cuerpo de las mujeres se hace evidente en este capítulo, titulado como "El arte de llegar a ser cosa" (Fig. 9):

"Todo un arte ¿quién lo duda? Un ejercicio constante, una sensibilidad a flor de piel, una dieta severa, vecina del hambre, amenazadora de enfermedades, de depauperación, para lograr esta bellísima muñeca sin tripa ni moca, una bellísima muñeca que casi flota fuera del espacio y del tiempo. ¿Es realmente un ideal de mujer?" (Capmany, 1977, p. 155).

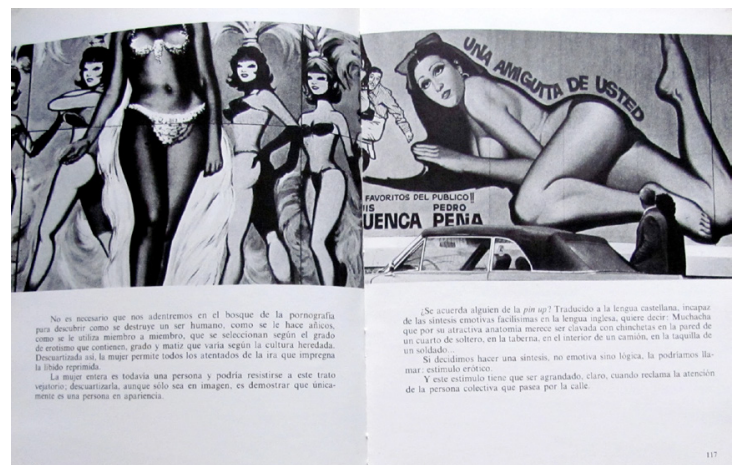

Figura 8. Antifémina. Madrid: Editora Nacional, 1977, p. 116 y 117. MNCARS 


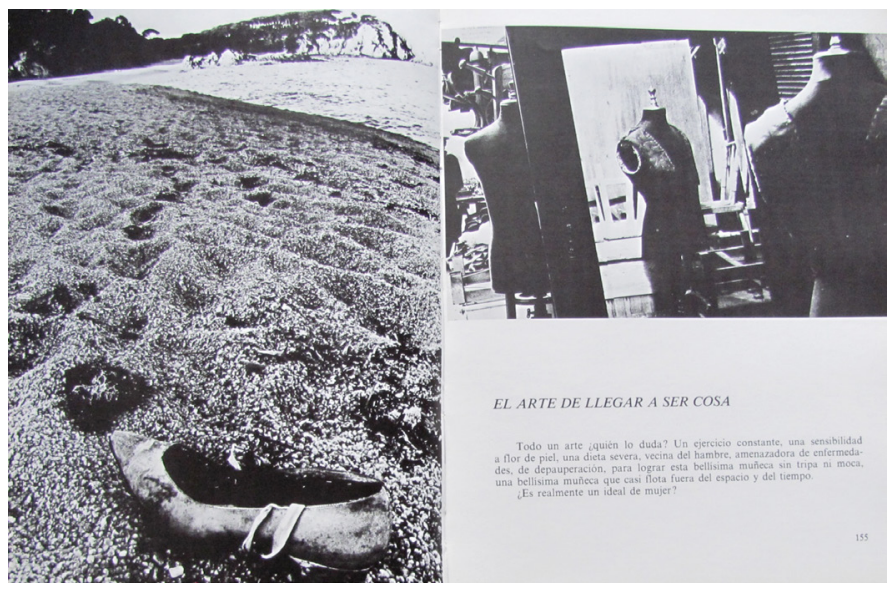

Figura 9. Antifémina. Madrid: Editora Nacional, 1977, p. 154 y 155 . MNCARS

Sin duda, como muestra la profusión de artículos en Vindicación feminista sobre el "destape", este sí fue un tema de actualidad que pasaba por una reflexión en la que interseccionaron la crítica feminista y la cultura visual. Además, los artículos de Vindicación y las ponencias que se ofrecieron en las distintas jornadas no se quedaron en la casposa producción patria sino que los debates transcendieron, y como ocurría en el ámbito internacional, llegaron hasta el abordaje de la pornografía, tema sobre el que aún hoy no existe consenso en el feminismo, dividido entre quienes sostienen su abolición y quienes se sitúan en la línea "prosexo".

Sobre la sexualidad femenina se publicó un número en Vindicación ( $n$ ㅇ 28, julio de 1979) en el que se reprodujeron los resultados de una encuesta que se hizo en la calles de Barcelona. Un artículo en el mismo número escrito por Lidia Falcón ${ }^{19}$ hacía un Ilamamiento a que las mujeres fuesen dueñas de su placer, a través de la separación de la sexualidad y la reproducción (para ello el uso de anticonceptivos por supuesto era esencial) pero también de la masturbación y el control del orgasmo. Orgasmo que, según datos de la encuesta no muchas mujeres habían tenido en sus relaciones heterosexuales de pareja, al confiar su cuerpo y su sexualidad a las brutales prácticas sexuales de los hombres; el llamamiento del artículo era el de que las mujeres se hiciesen dueñas de su propio cuerpo, algo a lo que también contribuyó el diseño visual del que se encargó Colita, con esa icónica portada en la que sobre el primer plano de un rostro de mujer casi en éxtasis, se escribía la mítica frase "el placer es mío, caballero" (Fig. 10). Los resultados del informe se acompañaron de una dinámica y ágil composición visual, que también fue obra de Colita; muchas de las fotografías que se publicaron son también de su autoría y ya habían sido utilizadas en Antifémina ${ }^{20}$.

Las feministas de los setenta se encargaron de politizar el placer sexual y erótico, entendido éste como una posible estrategia de empoderamiento vital femenino y una resistencia al heteropatriarcado. Al mismo tiempo, y también en relación con el placer aunque desde un ángulo bien diferente, Colita estaba realizando otro de tipo de fotografías, de muy distinta significación. Me refiero a su producción de fotografía erótica, que se puede contextualizar con ciertas tendencias relacionadas con el "destape" a través del protagonismo del cuerpo femenino desnudo o semidesnudo. El desnudo, por un lado, desafiaba la censura y los pacatos mandatos morales en torno al cuerpo de la sociedad española del último franquismo, pero lo cierto es 


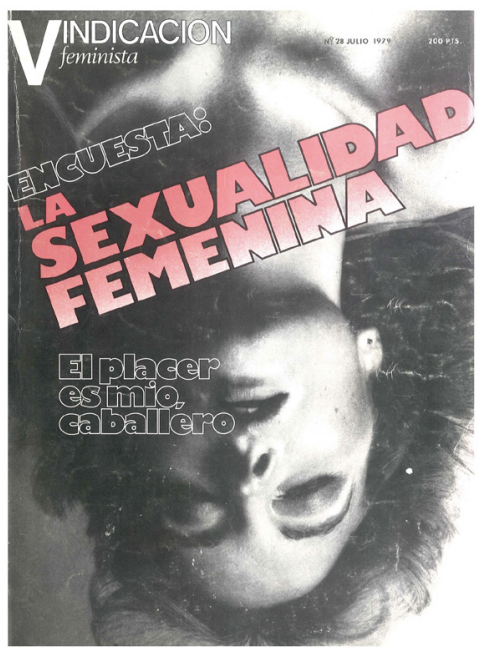

Figura 10. Vindicación feminista no 28, julio de 1979, portada. Foto Colita

que la cultura del "destape" se basó en una hipervisibilización y objetificación del cuerpo de las mujeres. No cabe duda de que fue un movimiento machista y acrítico, como subraya Garbayo (2016, p. 198), pero en su seno también existieron fracturas, audacias y posibles resistencias. Hasta el momento, las principales interpretaciones con perspectiva feminista/género entienden este fenómeno cultural como un territorio compacto y hegemónico, basado en la cosificación del cuerpo de las mujeres para una deseante y controladora mirada masculina. Estas interpretaciones, generalmente, siguen metodologías estructuralistas o posestructuralistas de corte psicoanalítico, muy influencias por el trabajo de Mulvey (2001) "Placer visual y cine narrativo", publicado originalmente en la revista Screen, en 1975 y que ha tenido un enorme impacto en la teoría feminista fílmica y de la representación en el Estado español ${ }^{21}$. El trabajo de Colita podría ser un primer paso para hacer una lectura feminista y queer de algunas formas del "destape", pues la que mira es una mujer y dirige el impulso erótico de su mirada hacia otra, que aparece en la fotografía mostrando autodeterminación y agencia. Es en este punto donde pensamos que el utillaje teórico ofrecido por Ahmed (2006) en su artículo titulado "Orientations: Toward a Queer Phenomenology" es relevante. Su propuesta consiste en "desorientar" las lógicas straight (heterosexuales) que construyen la experiencia, al considerar el "potencial queer de lo oblicuo" (Ahmed, 2006, p. 560). Estar orientado hacia uno u otro lugar supone que algunos cuerpos pertenezcan a algunos espacios y otros no; y también la orientación produce una dirección del deseo. Podríamos entender esta parte de la producción fotográfica de Colita como desorientada, desviada de una línea recta, y esto es así gracias al baile de miradas e identidades que se ponen en juego durante el acto fotográfico y en la posterior representación fotográfica; Colita invierte el orden de las cosas, su organización y dirección. Por otro lado, lo más agudo de su posicionamiento es el camuflaje una praxis queer (rara, invertida, marica) en una forma cultural hegemónica, pues al estar "desorientada" también evidencia su no pertenencia, la de una mujer haciendo fotografía erótica con otra como modelo. Esto también puede tener que ver con el significado cultural del concepto de armario que propone Capdevila-Argüelles (2016): funciona, en un plano simbólico, tanto como ocultación como, de puertas adentro, es un teatro o escaparate para la exposición de la identidad. También tiene que ver con ciertas tácticas que se utilizaron frecuentemente durante el franquismo, como el disimulo. 
El cruce de miradas que establecen en el acto fotográfico también se interpretaba en la época desde la idea de control y poder. Aunque fue algo muy poco evidenciado desde el discurso teórico por los fotógrafos del momento, contamos con las palabras de Miserachs, uno de los maestros de Colita, quien entendió las sinergias del retrato fotográfico como un "acto de posesión": "si retrato a una nena guapa y la madre insiste en que no salga muy escotada, me parece perfectamente comprensible, porque yo tengo la sensación de estar violándola, de estar haciéndola mía. Si algo tiene la fotografía es que es posesión pura. Y conviene que así siga". A lo que Colita responde que "para hacer un buen retrato es innegable que hay vampirizar al personaje" (Colita, Xavier Miserachs, 1988, p. 41). Desde esta perspectiva, ¿cómo interpretar, entonces, esa fotografía erótica de Colita, a la que ya nos hemos referido, que apareció publicada en revistas como Bocaccio o en los anuarios de Everfoto, editados por José Má Artero y Carlos Pérez Siquier? Unas fotografías las de Colita que, contextualizadas con otras fotografías de los mismos anuarios, subrayan que el cuerpo de la mujer cargado de sensualidad fue un tropo, en el sentido de una dirección, esencial para entender la fotografía de la década de los setenta, como también lo fue el del travestí (siempre en transición de masculino a femenino). Trabajos que se pueden considerar de avanzada y que también son los síntomas de los que habló Picornell (2010) en su análisis sobre esa España travestí en transición, que trató desprenderse de la virilidad franquista a través símbolos de contrapoder en la época, como fue lo transgénero.

Colita, en diálogo con otros fotógrafos del momento como Schommer, Tony Catany, Oriol Maspons o César Lucas, hará fotografía en color - algo bastante inusual en su produccióny con un carácter alejado del documentalismo propio del "arte utilitario", más cercana a la fotografía creativa que estaba tomando fuerza y se imponía con el cambio a la década de los ochenta, donde el juego, el humor, la ironía y la concepción de la identidad desnaturalizada empezaron a ser muy significativos. En muchos casos son fotografías sueltas que provenían de foto-secuencias eróticas como la de la mujer en la cama con el oso de peluche (Fig. 11), que acaba haciendo el amor con el juguete - algo que según Colita molestó bastante a quien contempló el trabajo-; la secuencia de los devaneos del gorila bisexual con dos mujeres jóvenes y un chico (Fig. 12); o los trabajos documentando y retratando los espectáculos de la travestí Diva Paulovsky o los retratos al artista Ocaña, junto a su amante y amigo Camilo.

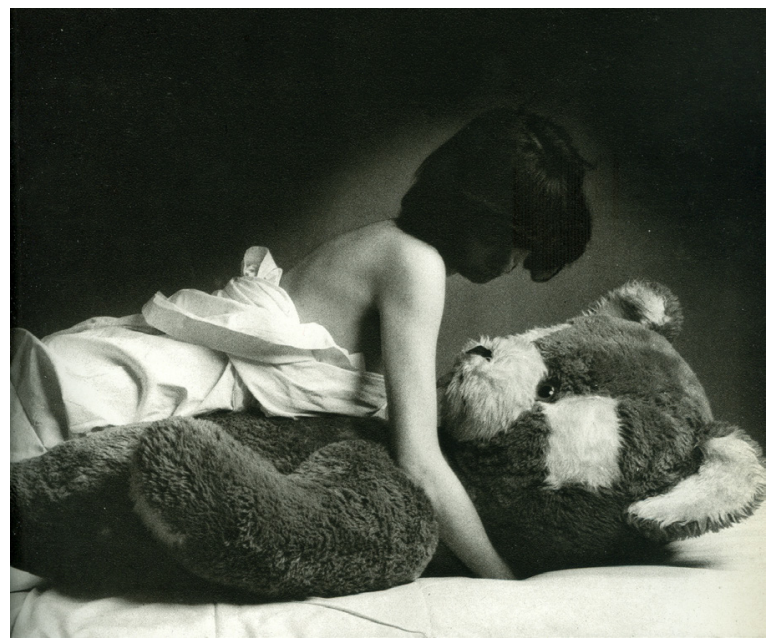

Figura 11. Colita. Fotografía publicada en Everfoto, vol. 4. León: Everest, 1976. 
Un trabajo que Colita califica de "revoltoso" al abordar el "transgénero" de forma pionera o "un erotismo contemporáneo donde la mujer mandaba (...) donde la mujer era dueña de sí misma. Su erotismo era para ella misma y no para los demás", según afirmó en la entrevista. Su manera de concebir el erotismo provocaba mucho, sigue argumentando la fotógrafa, pues desafiaba una idea que era esencial en la manera de concebirlo en la época: "el hombre piensa que la mujer se desnuda para él, pero la mujer se desnuda para mirarse ella misma en un espejo". Idea en la que de nuevo se pone la mirada en el centro, mirada entendida bajo el paradigma de poder y el control, pero que sin embargo en el planteamiento de Colita, el poder también emerge de la propia modelo.
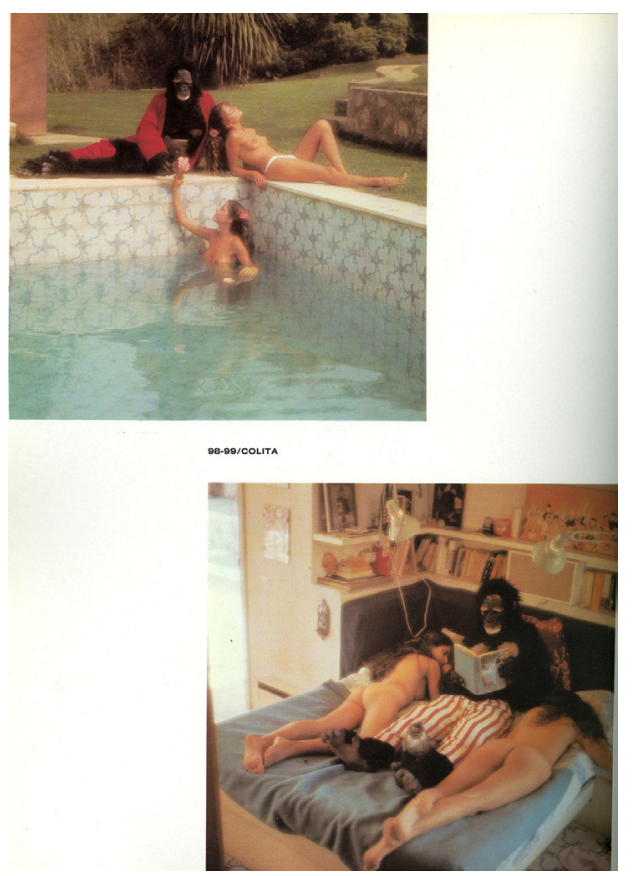

Figura 12. Colita. Fotografía publicada en Everfoto, vol. 5. León: Everest, 1980.

Estas ideas nos llevan al ya citado trabajo de Laura Mulvey (2001) A partir del marco teórico psicoanalítico, esta autora se interroga por los mecanismos de fascinación del cine, imbricados en las estructuras sociales y psíquicas de la sociedad patriarcal, el falocentrismo, y determinados por la diferencia sexual. Se pregunta por la estructuración de los modos de ver y el placer de la mirada que el cine narrativo de Hollywood, marcados por la escopofilia o voyerismo y el fetichismo, donde la mujer se constituye en el elemento pasivo/ imagen destinada únicamente a producir un impacto visual erótico, "para ser mirabilidad" (to-be-looked-at-ness) y el hombre, por el contrario es el activo portador de la mirada (Mulvey, 2001, p. 370), además de estructurar la relación de identificación de la mirada del espectador. Para Mulvey, la mujer es un icono erótico y el hombre el responsable de la acción, el ego ideal en el proceso de identificación. Sin embargo, parece que el planteamiento de Colita se sitúa más cerca de Kaja Silverman (1992, pp. 149 y 150), quien, siguiendo a Lacan, aboga por considerar, a través del concepto de pantalla - que distorsiona los límites entre el sujeto que mira y el objeto observable, y recordemos que Colita se refirió al espejo-, las relaciones especulares del sujeto representado, que puede exagerar, desnaturalizar o apropiarse a través de la mímica de un repertorio de gestos y actitudes 
(por ejemplo la seducción o la persuasión), devolviéndole así su agencia al modelo. La mujer ya no es sólo el sujeto pasivo y erótico para ser mirado, sino que este proceso representacional se torna en un arma de contestación cultural y social.

Esta fotografía se acompaña, como dice la propia Colita, de un cierto juego... "un juego muy personal, no estoy jugando con... estoy jugando conmigo. Este tipo fotografía tenía una provocación que a lo mejor otro tipo de fotografía, hecha por señores, no tenía"; el juego, en definitiva, era el del cuerpo y la mirada. Tal y como argumenta Laura Terré $(2010, \mathrm{~s} / \mathrm{p})$ en relación al trabajo de Colita, "todo puede parecer demasiado simple. Y en realidad lo es. Pero la facilidad y la sencillez no deben ocultar su profundidad y su rigor, por mucho que nos haga reír". Colita hacía foto erótica porque este era uno de los poderes de la mujer, "un poder que no era para provocarle a un señor una erección, sino para considerarse hermosa y poderosa". Esta fotografía, muy complicada de encontrar hoy en día, pues nunca pensó que esos juegos, esas "animaladas", "tuvieran sentido" y "solo hacía para divertirse", son seguramente la parte de su producción fotográfica que genera problemáticas más densas en relación con la imagen y la crítica feminista de la segunda ola. Ese poder por el que aboga, basado en la seducción y el cuerpo empoderado, no estaba muy lejos del que se criticaba en Antifémina, nos devuelve una constante ambigüedad que existe en las praxis fotográfica de Colita y seguramente sea donde podamos encontrar un posicionamiento más queer; algo tan sencillo pero a la vez tan poderoso como subvertir la mirada y el deseo, y comprenderlo como un viaje de dos direcciones, un juego de espejos que tiene que ver con la identidad. Subvertir la estructura de "autoridad" de un marco de encuadre cultural tan paternalista y poderoso como fue la fotografía erótica durante los años del "destape" español, es, seguramente, la apuesta más transgresora de Colita en relación a la praxis fotográfica. No solo porque sea ella la que mire, "desorientando" así la lógica de la mirada y el deseo heterosexual, sino porque dialoga con modelos que son mujeres empoderadas y con agencia que te interpelan, y es ahí, donde radica la potencia de su transgresión.

\section{Bibliografía}

Ahmed, S. (2006). Orientations: Towars a Queer Phenomenology.

GLQ: A Journal of Lesbian and Gay Studies, 12(4), 543-574.

Almerini, K. (2014). LaSal, bar-biblioteca feminista en Barcelona. Empoderamiento femenino y cultura visual. Boletín de Arte, 35, 83-100.

Bassas, A. (2013). Feminismo y arte en Cataluña en las décadas de los sesenta y setenta. Escenas abiertas y escenas de reflexión. En J. V. Aliaga y P. Mayayo (Ed.), Genealogías feministas en el arte español: 1960-2010 (pp. 215-236). Madrid: This Side Up.

Butler, J. (2007). El género en disputa. El feminismo y la subversión de la identidad. Paidós: Barcelona. 
Capdevila-Argüelles, N. (2016). Introducción. En E. Fortún, Oculto sendero (pp. 7-68). Sevilla: Renacimiento.

Capmany, M. A. (1977). Antifémina. Madrid: Editora Nacional.

Calvo, C. (2014). Antifémina. En fotos y libros. España 1905-1977 (pp. 234-236). Madrid: MNCARS.

Castro García, A. (2009). La representación de la mujer en el cine español de la Transición (1973-1982). Oviedo: KRK.

Colita, Xavier Miserachs (conversa transcrita per Xavier Febrés). (1988). Barcelona: Ajuntament de Barcelona.

Combahee River Colective (1977/2012). Un manifiesto feminista Negro. En R. L. Platero (Ed.), Intersecciones: cuerpos y sexualidades en la encrucijada (pp. 75-86). Barcelona: Bellaterra.

Garbayo, M. (2016). Cuerpos que aparecen. Performance y feminismos en el tardofranquismo. Bilbao: Consonni.

Llinás Carmona, C. (2008). Feminismes de la Transició a Catalunya. Textos i materials. Barcelona: Horsoni Editorial.

Lugon, O. (2010). El estilo documental. De August Sander a Walker Evans 1920-1945. Salamanca: Ediciones Universidad de Salamanca.

Mulvey, L. (2001). Placer visual y cine narrativo. En B. Wallis (Ed.), El arte después de la modernidad (pp. 365-377). Madrid: Akal.

Navarrete, C; Ruido, M y Vila, F. (2005). Trastornos para devenir: entre artes y políticas feministas y queer en el Estado español. En J. Carrillo, I. Estella y L. García-Merás (Eds.), Desacuerdos 2. Sobre arte, políticas y esfera pública en el Estado español (pp. 158-187). San Sebastián/Barcelona/Sevilla: Arteleku/MACBA/UNIA.

Pernas, B. (2012). Voces del lesbianismo en Vindicación feminista. En R. Osborne (Ed.), Mujeres bajo sospecha. Memoria y sexualidad (1930-1980) (pp. 397-407). Madrid: Fundamentos.

Picornell, M. (2010). ¿De una España viril a una España travesti? Transgresión transgénero y subversión del poder franquista en la transición española hacia la democracia. Feminismo/s, 16, 281-304.

Ribalta, J. (2008). Joan Fontcuberta como historiador de la fotografía española. En J. Fontcuberta, Historias de la fotografía española. Escritos 1977-2004 (pp. 7-17). Gustavo Gili, Barcelona. 
Ribalta, J. (2015). Prefacio, en Aún no: Sobre la reinvención del documental y la crítica de la modernidad (1972-1991) (s/p), MNCARS, Madrid.

Rich, A. (1986). Sangre, pan y poesía. Icaria: Barcelona.

Rubin, G. (1975). The Traffic in Women: Notes on the Political Economy of Sex. En R. Reiter (Ed.), Toward and Anthropology of Women (pp. 157-210). Nueva York: Monthly Review Press.

Silverman, K. (1992). Male Subjetivity at the Margins. New York y Londres, Routledge.

Terré, L. (2010). Colita ¡Yo no soy un espejo!, en Colita (s/p). Madrid: La Fábrica.

Terré, L. (2014). Colita fotografía, Barcelona. Barcelona: Fundació Catalunya-La Pedrera.

Uría Ríos, P. (2009). El feminismo que no llegó al poder. Trayectoria de un feminismo crítico. Madrid: Talasa.

Wittig, M. (2006). El pensamiento heterosexual y otros ensayos. Madrid/Barcelona: Egales.

\section{NOTAS}

1. Una primera versión de este ensayo se presentó en el seminario "Documental y neovanguardia. Prácticas fotográficas en los años 70" (mayo de 2015, Museo Nacional Centro de Arte Reina Sofía). Agradezco a Jorge Ribalta y a Chema González la invitación, que sirvió de motivación para adentrarme en este tema.

Gracias también a Jesusa Vega, Lucas Platero, Iñaki Estella, Laura Terré, Concha Calvo Salanova y Ona Bros, pues con sus valiosas ideas y aportaciones he podido escribir estas líneas. Muy agradecida especialmente a las fotógrafas Pilar Aymerich y Colita, quienes abrieron sus archivos fotográficos y su memoria cuando las visite en febrero de 2015 en Barcelona. Este ensayo se ha escrito en el marco del proyecto de investigación EUESF HERA.15.099-CRUSEV: "Cruising the 1970s: Unearthing Pre-HIV/AIDS Queer Sexual Cultures".

2. Para una aproximación general a su trabajo, ver la página web de la fotógrafa: http://www. colitafotografia.com/ (consulta: 19/01/2017)

3. Los historiadores del cine marcan el inicio de este fenómeno, conocido como "destape", en febrero de 1975 cuando se aprueban una serie de normativas que regulan la industria; un año más tarde se suprime la censura previa de guiones. El proceso culmina con la aprobación, en noviembre de 1977, de la eliminación oficial de la censura y el establecimiento de una 
cuota de pantalla por la que cada sala deberá proyectar cine español al menos ciento veinte días al año (Castro García, 2009, p. 47).

4. Su punto de partida, como decía el primer número de la revista, de junio de 1976, era el de "llegar al mayor número posible de mujeres de todos los estratos sociales, por lo que debemos tratar un extenso mosaico de problemas y temas que les afecten particularmente", entre los cuales se destacan: promoción laboral y profesional; deficiencias de la legislación civil; situaciones conflictivas de la familia y la información sobre los movimientos de liberación de la mujer en todo el mundo.

5. Entre 1976 y 1980, Colita publicó también fotografías y reportajes en Interviú. El trabajo de Colita en este medio no se dedicó a la fotografía erótica sino que presentó una fotografía documental descarnada y de denuncia social.

6. Colita fue llevada a los tribunales por una serie que publicó en esta revista donde se podía ver a su amiga Teresa Gimpera con una bata de seda (Terré, 2014, p. 165).

7. Más de 4000 mujeres ocuparon el Paraninfo de la Universitat de Barcelona; a pesar de que las organizadoras esperaban unas 600 .

8. Ideas extraídas de la conversación con Colita en su estudio de Barcelona el 12 de febrero de 2015 , la cual fue grabada. A partir de este punto, todas las referencias a la voz de Colita que no estén citadas a través de otra fuente se refieren a esta misma conversación.

9. Colita piensa que la buena fotografía ha de tener un componente "humanístico". Tal y como expuso en la conversación que mantuvimos, es un concepto que quiere reivindicar en la actualidad, en clara conjunción con la concepción de la fotografía documental que se creó durante la década de los cuarenta, en la que los valores de registro, archivo y objetividad dieron paso al "contenido humano" y "sentimental" (Lugon, 2010, pp. 103116). Esta idea del documento fotográfico se consolidó en la mítica exposición que comisarió Edward Steichen para el MoMA, titulada The Family of Man (1955); exposición que ella y los fotógrafos catalanes de su generación consideraron su escuela y también su referente. Sin embargo, tal y como expone Ribalta, ese componente humanista presente tanto en esta muestra como también en la revista Life, fue uno de los principales vehículos para neutralizar la cultura fotográfica revolucionaria del periodo de entreguerras, pues impuso en el "discurso fotográfico documental en Occidente un inconsciente paternalista y conciliador de fraternidad universal, justificado principalmente por el trauma de la guerra, así como por la geopolítica cultural de la Guerra Fría" (Ribalta, 2015, s/p).

10. Tuve oportunidad de reunirme con Pilar Aymeric en su estudio de Barcelona el 12 de febrero de 2015.

11. Vindicación feminista, nㅇ 6, 1 de diciembre de 1976, p. 16 y Interviú, nํ 28, 25 de noviembre de 1976, pp. 78 y 79.

12. Vindicación feminista no 19, 1 de enero de 1978, pp. 28-37 y los siguiente números de Interviú: no 41, 24 de febrero de 1977, pp. 26 y 27; no 50, 28 abril de 1977, pp. 56-58; 으 51, 5 de mayo de 1977, pp. 34-36 y no 52, 12 mayo de 1977, pp. 62-64. 
13. Fueron escritos por Alicia Fajardo, Txiki Laorden y Pilar Mosqueda.

14. Sobre este tema encontramos publicadas las mismas fotografías en Vindicación feminista, no 10,1 de abril de 1977, pp. 22; 47 y 36. Por otro lado, en el libro Antifémina, en pp. 72; 77 y 80. Así mismo encontramos las mismas fotografías en Vindicación Feminista no 11, 11 de mayo de 1977, pp. 31 y 35, que coinciden con las pp. 71 y 70 de Antifémina, respectivamente.

15. En relación a la prostitución, las fotografías presentes en Vindicación feminista no 2, 1 de agosto de 1976, pp. 27-29 también se encuentran en Antifémina entre las pp. 104 -109.

16. La fotografía que sobre el divorcio ilustra Vindicación feminista $\mathrm{n}-15,1$ de septiembre de 1977, pp. 18 también se pueden ver en Antifémina, p. 57.

17. Se trata de la entrevista de J. Fabre a Colita y Maria Aurèlia Capmany: "La Nova Cançó ya es historia en fotos", en Tele-eXpres, Barcelona, 5 de septiembre de 1978.

18. Capmany prologó la traducción catalana de Beauvoir, publicada en 1968 por Edicions 62 . El libro circulaba en castellano desde 1962, gracias a una edición argentina del Siglo XX. Otras lecturas feministas clave para Capmany fueron La mística de la feminidad, de Betty Friedan que se tradujo al castellano en 1963 (mismo año de su publicación original en EEUU); los trabajos de María Laffite, condesa de Campo Alange La secreta guerra de los sexos (1948) y La mujer en España. Cien años de su historia 1860-1960 (1963) o Virginia Woolf, especialmente la novela Orlando y el ensayo Tres Guineas (Bassas, 2016).

19. Falcón, L. "Ser dueñas de nuestro cuerpo y nuestro placer", Vindicación feminista, no 28, julio de 1979, págs. 5-7.

20. Véanse la doble página 20 y 21 de Vindicación feminista ( $n$ o 28, julio de 1979) en comparación con la 118 y 119 de Antifémina. También la página 29 del mismo número de Vindicación y la 167 de Antifémina.

21. Como señalan Navarrete, Ruido y Vila (2005, p. 172), la traducción de este artículo al castellano en 1988, por la colección Eutopías de la Universidad de Valencia, fue fundamental en el panorama español, calificado por esta autoras de "paupérrimo" en relación a la crítica de la representación feminista. 